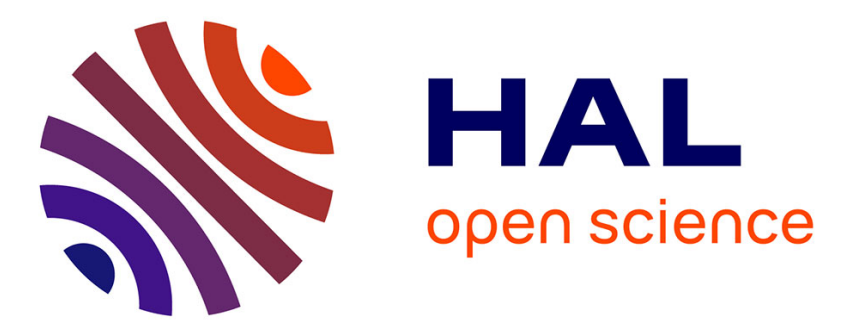

\title{
Mechanical Spectroscopy of the Carbon Snoek Relaxation in Ultra-High Purity Iron
}

L. Magalas, Gilbert Fantozzi

\section{To cite this version:}

L. Magalas, Gilbert Fantozzi. Mechanical Spectroscopy of the Carbon Snoek Relaxation in Ultra-High Purity Iron. Journal de Physique IV Proceedings, 1996, 06 (C8), pp.C8-151-C8-154. 10.1051/jp4:1996831 . jpa-00254639

\section{HAL Id: jpa-00254639 https://hal.science/jpa-00254639}

Submitted on 1 Jan 1996

HAL is a multi-disciplinary open access archive for the deposit and dissemination of scientific research documents, whether they are published or not. The documents may come from teaching and research institutions in France or abroad, or from public or private research centers.
L'archive ouverte pluridisciplinaire HAL, est destinée au dépôt et à la diffusion de documents scientifiques de niveau recherche, publiés ou non, émanant des établissements d'enseignement et de recherche français ou étrangers, des laboratoires publics ou privés. 


\title{
Mechanical Spectroscopy of the Carbon Snoek Relaxation in Ultra-High Purity Iron
}

\author{
L.B. Magalas and G. Fantozzi*
}

University of Mining and Metallurgy, Akademia Górniczo-Hutnicza, AGH, Faculty of Metallurgy and Materials Science, Al. Mickiewicza 30, 30059 Kraków, Poland

* INSA de Lyon, GEMPPM, Bât. 502, 69621 Villeurbanne cedex, France

\begin{abstract}
Low and very low frequency mechanical loss spectra of the stable carbon Snoek relaxation in ultra-high purity $\alpha$-Iron doped with 1000 at. ppm of carbon were carried out. The carbon Snoek peak was analyzed by various numerical methods in order to determine its relaxation parameters. The following mean values of the relaxation parameters were found: the activation enthalpy $H^{S}=0.878 \mathrm{eV}$ and the preexponential factor $\tau_{\infty}=1.71 \cdot 10^{-15} \mathrm{~s}$. The observed height of the stable carbon Snoek peak in saturated $\alpha$-Iron $Q_{\max }^{-1}=2.8 \cdot 10^{-2}$ is to our knowledge the highest ever reported in the literature.
\end{abstract}

\section{INTRODUCTION}

In the framework of mechanical spectroscopy the complex compliance $S(\omega)$ is given by the one-sided Fourier transform of the response function $\phi(t)$ (or of the derivative of the normalized relaxation function which describes mechanical relaxation for quasi-static perturbation) $[1,2]$ :

$$
S(\omega)=S_{U}+\int_{0}^{\infty} \phi(t) \exp (i \omega t) d t
$$

where $S_{U}$ is the unrelaxed compliance and $\omega$ is the angular frequency. For normalized Debye relaxation

$$
S(\omega)=S^{\prime}(\omega)-i S^{\prime \prime}(\omega)=S_{U}+\frac{\delta S}{\tau} \int_{0}^{\infty} \exp (-t / \tau) \exp (i \omega t) d t=S_{U}+\delta S \frac{1}{1-i \omega \tau},
$$

where $\delta S=S_{R}-S_{U}$ is the relaxation of compliance, $S_{R}$ is the relaxed compliance and $\tau$ is the relaxation time. The complex compliance $S(\omega)$ may be written in the form of its real and imaginary parts:

$$
S^{\prime}(\omega)=S_{U}+\delta S \frac{1}{\left(1+\omega^{2} \tau^{2}\right)}, \quad S^{\prime \prime}(\omega)=\delta S \frac{\omega \tau}{\left(1+\omega^{2} \tau^{2}\right)} .
$$

Mechanical loss peak for a single Debye relaxation can be expressed by the mechanical loss $\operatorname{tangent} \tan \varphi$ for low values of energy losses, that is, for negligible difference between the relaxation time under constant stress and constant strain [1]:

$$
\tan \varphi=Q^{-1}(\omega \tau)=\frac{S^{\prime \prime}(\omega)}{S^{\prime}(\omega)}=\frac{\delta S}{S_{R}} \frac{\omega \tau}{\left.1+\left(\frac{S_{U}}{S_{R}}\right) \omega^{2} \tau^{2}\right]}=\Delta \frac{\omega \tau}{\left(1+\omega^{2} \tau^{2}\right)},
$$

where $\Delta \equiv \delta S / \bar{S}$ is the relaxation strength and $\bar{S}=\left(S_{U} S_{R}\right)^{1 / 2}$ is the geometric mean of the moduli. $\tau$ is the microscopic relaxation time, which obeys the Arrhenius equation $\tau^{-1}=\tau_{\infty}^{-1} \exp (-H / k T)$, where $\tau_{\infty}^{-1}$ is the preexponential factor, $H$ is the activation enthalpy, $k$ is the Boltzmann constant and $T$ is the absolute temperature. The purpose of this paper was to obtain the relaxation parameters of the carbon Snoek peak described by Eq. (4) in ultra-high purity $\alpha$-Iron. It was accomplished by numerical determination of the peak position from mechanical loss measurements. The peak position as a function of temperature at three 
constant frequencies, $\tan \varphi=f(T)$, and as a function of frequency, $\tan \varphi=f(\omega)$, where $\omega=2 \pi \mathrm{f}$ and $\mathrm{f}$ is the oscillation frequency was determined.

\section{THE SNOEK RELAXATION}

The Snoek relaxation is a typical example of Debye mechanical relaxation. It results from a statistical redistribution of a set of identical, non-interacting elastic dipoles, which is accomplished by thermally activated jumps between crystallographically equivalent positions (see Fig. 1.a) degenerated energetically under the action of an applied time-dependent mechanical field as illustrated in Fig. 1.b. In other words, the Snoek relaxation is the stress-induced short-range redistribution of point defects that have symmetry lower than the symmetry of the crystal in which they reside. For example, the presence of foreign interstitial atoms (FIAs) in octahedral sites in bcc metals creates 'elastic dipoles' around them with a tetragonal strain field. The symmetry condition requires the existence of more than one equivalent position of the point defect in the host lattice as shown in Fig. 1.
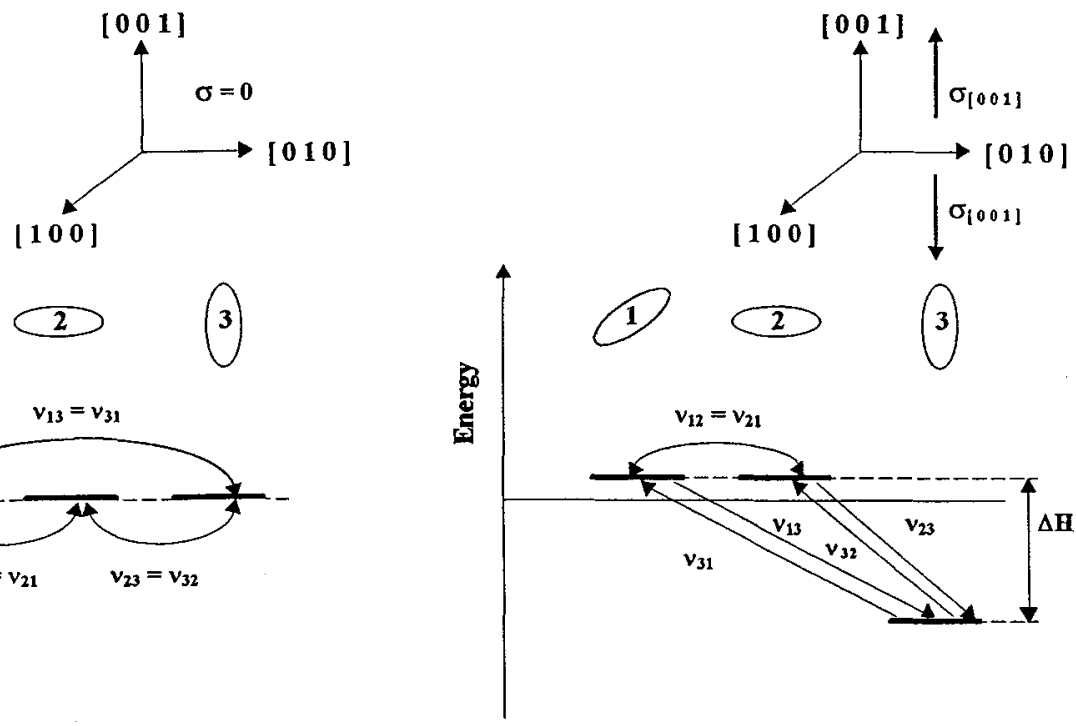

(a)

(b)

Figure 1: Schematic representation of the elastic dipoles in the bcc lattice. The dipoles are oriented along $<100\rangle$ direction. (a) Energy level for the elastic dipoles in the absence of an external mechanical field (no preferential occupation of available sites), and (b) redistribution of energy levels under the action of an external stress field applied along [001].

For harmonic mechanical perturbation the energies of the positions available for the elastic dipoles are time-dependent leading to dipole redistribution toward the orientation with the lowest instantaneous energy. Therefore the reorientation of elastic dipoles is time-dependent. This means that there occurs a phase lag between mechanical polarization induced by reorientation of the elastic dipoles and an external stress field. The reorientation of the elastic dipoles proceeds by thermally activated jumps between different positions over a potential barrier $\Delta \mathrm{H}$ (see Fig. 1.b) with a microscopic relaxation time $\tau$. Temperature dependence of the microscopic relaxation time is determined by the Arrhenius equation.

A stochastic character of the motion of the elastic dipoles is not discussed in this paper.

\section{EXPERIMENTAL}

The samples used in this study were prepared from ultra-high purity $\alpha$-Iron pre-doped with 1000 at. ppm of carbon [3,4]. The polycrystalline wires were drawn to $1 \mathrm{~mm}$ in diameter and $80 \mathrm{~mm}$ in length, then 
subjected to carefully designed heat treatment in order to obtain very high concentration of carbon atoms in solid solution close to the maximum solid solubility of carbon atoms in ferrite [3]. A deformation texture of $\{110\}<111>$ typical for bcc metals, was observed in the investigated samples.

The loss of mechanical energy was measured as a function of temperature in a forced torsion pendulum operating at three different frequencies: $f=0.01, f=0.1$ and $f=1 \mathrm{~Hz}$. The first phase lag measurement was done at $f=0.01 \mathrm{~Hz}$, then the second at $f=0.1 \mathrm{~Hz}$, and finally the third one at $f=1 \mathrm{~Hz}$. Frequency sweeps in the low frequency range were carried out at different constant temperatures by phase lag measurements in the same mechanical spectrometer. An axial magnetic field of 140 Oe was applied in order to suppress magnetomechanical damping. The carbon Snoek peaks observed in two consecutive mechanical loss measurements as a function of temperature were the same, thus confirming excellent thermal stability of the investigated Snoek peak [3]. Our systematic study of ultra-high purity $\alpha$-Iron of different carbon concentrations [3] allowed to establish the optimal experimental conditions for observing the thermally stable carbon Snoek peak after saturation treatment. The carbon Snoek peak height, $Q_{\max }^{-1}$, and the peak temperature, $T_{\max }^{S}$, have been determined numerically by nonlinear optimization techniques.

\section{RESULTS}

Figure 2 shows the carbon Snoek peak in the studied ultra-high purity $\alpha$-Iron, containing 1000 at. ppm of carbon, obtained: (a) during temperature sweep for three frequencies: $f=0.01, f=0.1$ and $f=1 \mathrm{~Hz}$ (Fig. 2.a), and (b) under isothermal conditions (Fig. 2.b). The average height of the carbon Snoek peak was around $2.5 \times 10^{-2}$.

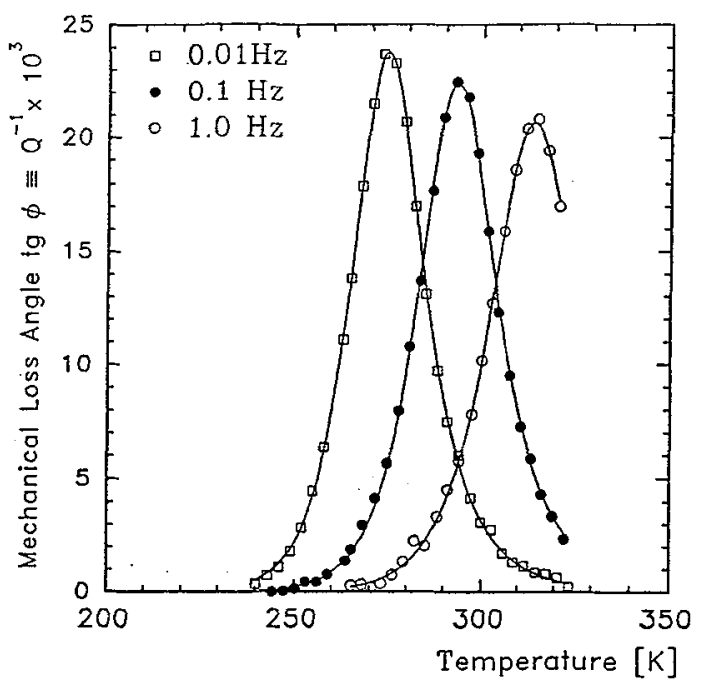

(a)

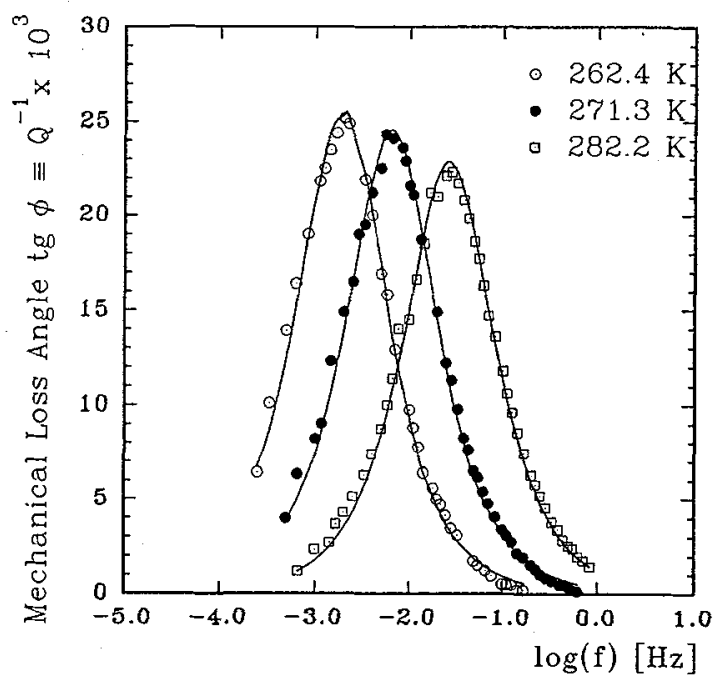

(b)

Figure 2: The carbon Snoek peak in ultra-high purity $\alpha$-Iron: (a) for three frequencies, and (b) for frequency sweep.

The activation enthalpy of the carbon Snoek peak was determined in samples containing nearly 1000 at. $\mathrm{ppm}$ in solid solution. The Snoek peak corresponding to different temperatures is shifted along the frequency axis according to the exponential temperature dependence of the relaxation time. The Arrhenius plot of the carbon Snoek peak in $\alpha$-Iron is shown in Fig. 3. It yields an activation enthalpy of the carbon Snoek relaxation $H^{S}=0.878 \mathrm{eV}$ and a preexponential factor $\tau_{\infty}^{-1}=1.21 \times 10^{-15} \mathrm{~s}$. It is noteworthy that in the obtained Arrhenius plot numerous experimental points have the same value. More detailed analysis of the carbon Snoek peak in ultra-high purity $\alpha$-Iron will be reported elsewhere [4]. 


\section{DISCUSSION}

The measurements were performed under the conditions assuring excellent thermal stability of the carbon Snoek peak, i.e. no peak evolution during the mechanical loss measurements was observed. This allowed us to determine reliable relaxation parameters. On the basis of transmission electron microscopy observations it was found that the stable Snoek peak was obtained only if ferrite did not contain heterogeneous places for carbide precipitation. In this case, precipitation of fine carbides started after 20 to $22 \mathrm{hrs}$ of aging at $290 \mathrm{~K}$. The Arrhenius plot yields an activation enthalpy of the carbon Snoek relaxation. $H^{S}=0.878 \mathrm{eV}$, and a preexponential factor of $\tau_{\infty}^{-1}=1.21 \times 10^{-15} \mathrm{~s}$, corresponding to $T_{\max }^{S}=313.46 \mathrm{~K}$ (for $f=1 \mathrm{~Hz}$ ). Similar results were reported for iron pre-doped with lower carbon concentration $(45 \div 600$ at. ppm) [5]. Additional experimental data obtained in an inverted torsion pendulum working at resonant frequency around $1 \mathrm{~Hz}$ and mechanical aftereffect data may modify the reported preliminary results on the relaxation parameters of the carbon Snoek peak in $\alpha$-Iron. In this paper we deliberately did not discuss secondary features of the carbon Snoek peak related to broadening effect. We point out, however, that to our knowledge the observed carbon Snoek peak height is the highest ever reported in the literature.

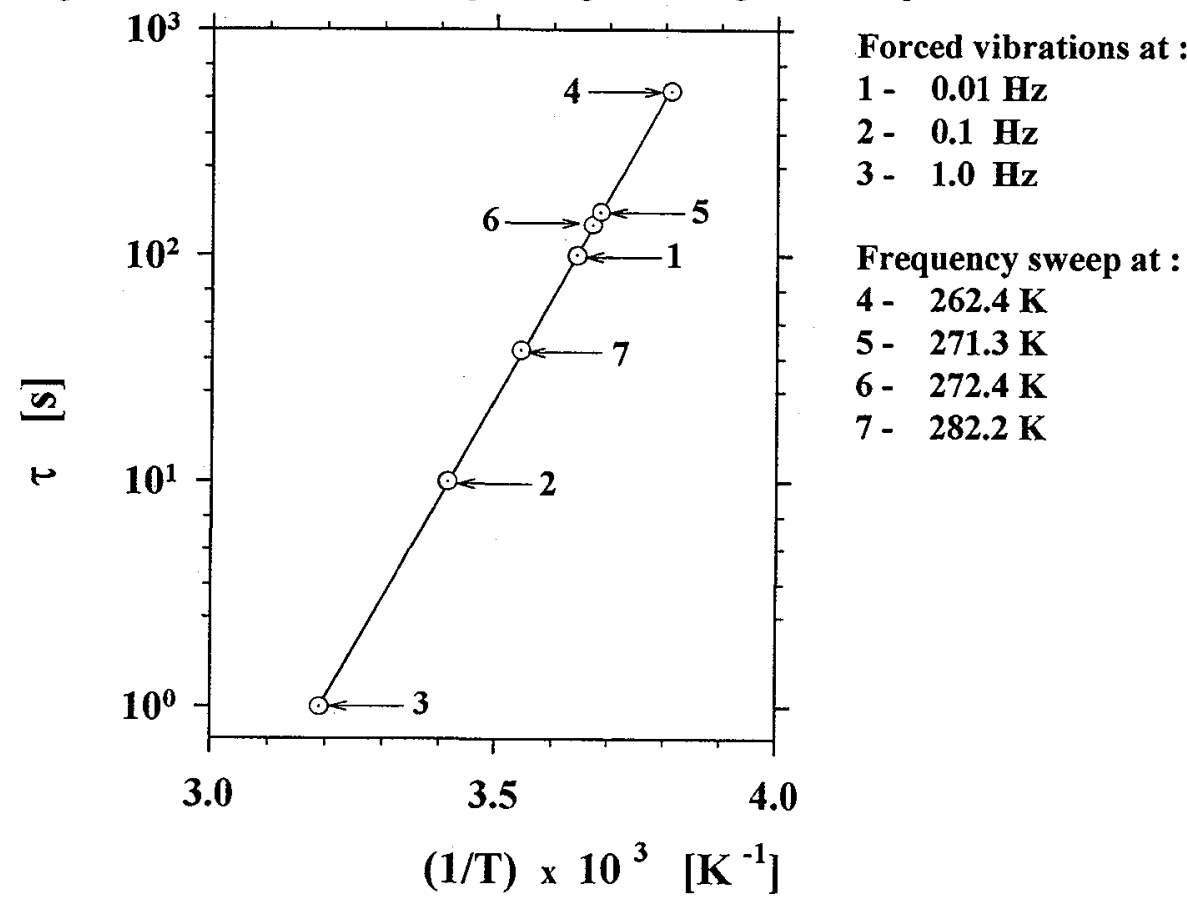

Figure 3: Arrhenius plot for the carbon Snoek peak in ultra-high purity $\alpha$-Iron measured with a forced low torsion pendulum.

\section{Acknowledgments}

This work was supported by the Polish State Committee for Scientific Research (KBN) under grant No. 7 T08B 04308 .

\section{References}

[1] Nowick A.S. and Berry B.S., Anelastic Relaxation in Crystalline Solids, Academic Press, New York and London, 1972.

[2] Magalas L. B., Introduction to Mechanical Spectroscopy, in Mechanical Spectroscopy, 1997 (in press).

[3] Magalas L.B. and Fantozzi G., to be published.

[4] Vanoni F., These, Universite de Grenoble, 1973.

[5] Haneczok G., Weller M. and Diehl J., Materials Science Forum, 119-121 (1993) 101-106. 